\title{
E-health in Preparedness and Response
}

James J. James, MD, DrPH, MHA, Director, Center for Public Health Preparedness and Disaster Response; Lauren Walsh, MPH, Research Associate, Public Health Readiness Office, American Medical Association

I $\mathrm{t}$ is well known that the United States currently spends more per capita on health care than any other nation. Much of this expenditure, about $\$ 1.8$ trillion, is spent on medical costs associated with chronic diseases such as diabetes, heart disease, and cancer. ${ }^{1}$ While more than 109 million Americans report having at least one chronic disease, ${ }^{2}$ many could not tell you the name, type, or dosages of medications they have been prescribed. One report found that more than fifty percent of patients with chronic disease had at least one unintended medication discrepancy at the time of hospital admission. ${ }^{3}$ This is especially problematic, as optimal patient care depends upon accurate and timely communication of health conditions, medications, and sources of care.

In times of disaster, when resources are low and time is limited, health care providers are especially pressed to access and collect accurate personal health information from their patients. Access and availability issues are exacerbated due to lost medical records, evacuees not carrying proof of personal identification, and injured and ill patients who cannot effectively communicate their health care needs. Electronic health records (EHRS) may provide a solution, but they are not currently universally implemented, nor are hospital network EHR systems necessarily accessible by physicians outside the network. Patient-owned personal health records (PHRs) may be another potential solution, but little has been done to investigate uptake potential among the American public, or the utility and feasibility of PHRs during disasters. ${ }^{4}$

As the largest health-science library in the world, the $\mathrm{Na}$ tional Library of Medicine is optimally positioned to assist in collating and distributing the available literature in this area. ${ }^{5}$ As their Disaster Information Management Research Center (DIMRC) has already begun to organize existing disaster literature, they are perhaps the most reliable source of information regarding the potential role of EHRs and PHRs in patient identification and continuity of care following a disaster. The DIMRC's expertise in library and information science is vital to this endeavor, in that they can also provide an educated assessment of work done outside of academia-work that is found in the so-called "gray" literature. While this form of literature lacks the academic rigor of peer review, it is no less important than formally published papers because it documents empirical research that may not be published elsewhere. As implementation of e-health systems depends on the collaboration of many sectors, including medicine, public health, health informatics, health information technology, and public and private business entities, there is likely relevant information to be found outside the realm of traditional disaster health information sources.
While EHRs and PHRs may prove to be a solution for continuity of care and patient identification issues following a disaster, they should not be regarded as a one-stop shop for improving our national response capability. Looking at the direction in which e-health is currently headed, it is clear that a strong connection must be made between education and training, communication systems, and public health surveillance. As it stands, these components are far too often seen as separate entities in the realm of disaster response and recovery, when they should instead be integrated into an interrelated information system that can help us better coordinate our efforts and ensure the health and well-being of our nation during disasters.

From a worldwide perspective, America is quite behind in establishing effective e-health systems. Many European nations already have national systems, which can both verify the identity of a person and provide accurate information regarding the health history and current health care needs of an individual. ${ }^{6}$ All of these systems depend on some form of portable vehicle to store information; these can include printed materials and magnetic strips. Embedded chipswhether held in a card or a piece of jewelry, or placed under a person's skin-may well be the wave of the future and have already been embraced in countries such as France and Germany. Chips safely and securely hold a large amount of information; they are also less susceptible to damage, convenient to carry, and offer multiple layers of identity protection. Implementation of a chip-based system could allow us to facilitate a public health tool which, in major events such as Hurricane Katrina, could well enable a more effective and timely medical and public health response.

Based on our experiences at the American Medical Association in dealing with Katrina and its aftermath, we wrote a proposal to evaluate the feasibility and acceptability of a "Health Security Card" as a population-based public health tool that would allow for: (1) biomarker-confirmed identification; (2) expeditious notification of family members and caregivers; and (3) immediate availability of basic medical information to health responders-all in a secure digital environment to help ensure protection of privacy. An additional feature of the card would allow it to be used as a "key" to access an individual's full electronic medical record should Internet connectivity be available. This proposal was funded by CDC, and we are entering the final year of a three-year grant.

With all of the developments in digital applications and e-health, the CDC grant has provided an exciting opportunity to evaluate the concept of a portable, personalized health in- 
formation system in enhancing response to disasters and public health emergencies. Several papers will be submitted to publish our research findings, with a particular focus on public acceptability of a Health Security Card and demonstration of its applicability in a field environment. Still, there are many barriers to deploying a chip-based Health Security Card. Primary among these are lack of an individual health identifier that would allow access to information across systems, the many proprietary applications that support and essentially Balkanize major health information systems, population-based concerns about private health information, economic dependency on legacy systems that almost precludes change and modernization, and a continuing need to unite disparate interests for the public good.

As formidable as these obstacles seem, they can be and are being overcome, and the common transformational element in propelling these changes is the rapid expansion of e-health applications utilizing cloud computing and social networking, as well as an increasing willingness of individuals to assume primary responsibility for their own health care and thus the health security of our nation.

\section{REFERENCES}

1. The United Health Foundation. America's Health Rankings: A Call to Action for Individuals and Their Communities. Edition; 2010.

2. De Vol R, Bedroussian A, Charuworn A, et al. An Unhealthy America: The Economic Burden of Chronic Disease-Charting a New Course to Save Lives and Increase Productivity and Economic Growth. Milken Institute. October 2007.

3. Cornish PL, Knowles SR, Marchesano R, et al. Unintended medication discrepancies at the time of hospital admission. Arch Intern Med. 2005;165 (4):424-429.

4. Pontini VC, Weerasuriya DN, Lowery-North DW, et al. Commercial products that convey personal health information in emergencies. Disaster Med Public Health Prep. 2011;5:261-265.

5. Phillips SJ. The importance of journals to the growing discipline of disaster medicine. Disaster Med Public Health Prep. 2011;5:259-260.

6. e-Health ERA. Information, society, and media. Database of European e-health priorities and strategies. http://www.ehealth-era.org/database /database.html. Accessed October 25, 2010. 